\title{
Medical foster care: what happens when children with medical complexity cannot be cared for by their families?
}

\author{
Rebecca R. Seltzer', Carrie M. Henderson ${ }^{2}$ and Renee D. Boss ${ }^{1,3}$
}

Medical interventions for life-threatening pediatric conditions often oblige ongoing and complex medical care for survivors. For some children with medical complexity, their caretaking needs outstrip their parents' resources and abilities. When this occurs, the medical foster care system can provide the necessary health care and supervision to permit these children to live outside of hospitals. However, foster children with medical complexity experience extremes of social and medical risk, confounding their prognosis and quality of life beyond that of similar children living with biologic parents. Medical foster parents report inadequate training and preparation, perpetuating these health risks. Further, critical decisions that weigh the benefits and burdens of medical interventions for these children must accommodate complicated relationships involving foster families, caseworkers, biologic families, legal consultants, and clinicians. These variables can delay and undermine coordinated and comprehensive care. To rectify these issues, medical homes and written care plans can promote collaboration between providers, families, and agencies. Pediatricians should receive specialized training to meet the unique needs of this population. National policy and research agendas could target medical and social interventions to reduce the need for medical foster care for children with medical complexity, and to improve its quality for those children who do.

$\mathbf{F}$ oster care involves removal of a child from their home, often due to neglect or abuse, with placement into a group facility or private home; a relative or nonrelative foster parent becomes the certified caregiver. As of 2013, approximately 400,000 children were in the foster care system in the United States (1). Overall, nearly $6 \%$ of all children experience foster care placement, though risk for entry is disparate: 1 in 7 Native American and 1 in 9 Black children enter foster care (2).

Children in foster care have often been exposed to social risk factors that drive pediatric health disparities, including poverty, single parent homes, family stress, maternal mental health concerns, minority race/ethnicity, and community and household violence $(3,4)$. It is not a surprise, then, that nearly half of the children in foster care have chronic medical problems and unmet health care needs (5). Importantly, there is a growing cohort of children who enter foster care specifically because they have complex medical needs that cannot be managed by families with limited resources. This particularly vulnerable pediatric cohort experience both extreme social and medical burdens-an interaction that promotes excess health hazards (4). Yet as medical advances expand the population of children with medical complexity, we lack systematic data about important medical and social outcomes that should guide decisionmaking and policy development. The nominal resources and attention directed at foster children with medical complexity leave many uncertainties about what could and should be done about the health of this population (6).

In this review, we will synthesize existing literature addressing whether medically fragile children in foster care fare better, worse or equal to similar children not in foster care. We will highlight data about the impact of social risks on medical risks for medically fragile foster children. We will also evaluate the utilization and effectiveness of foster care as a placement option for such children, drawing upon foster caregivers' experiences. Summarizing these issues will aid clinicians engaging in decisions about the benefits and burdens of interventions for these patients, and can inform health care policy and funding agendas.

\section{MEDICALLY COMPLEX CHILDREN: A GROWING POPULATION}

Children with Special Health Care Needs (CSHCN) is a population defined as, "... those who have or are at increased risk for a chronic physical, developmental, behavioral, or emotional condition and who also require health and related services of a type or amount beyond that required by children generally" $(7,8)$. Approximately $18 \%$ of children in the United States qualify as CSHCN (7), and in 2001 the Institute of Medicine identified CSHCN as a priority group for improving quality health care (9).

Within the larger group of CSHCN, an internal cohort bears the greatest burden of diagnoses, care complexity, and resource and/or technology consumption $(10,11)$. Historical terms to describe this cohort included "technology-dependent

\footnotetext{
'Department of Pediatrics, Johns Hopkins University School of Medicine, Baltimore, Maryland; ${ }^{2}$ Division of Pediatric Critical Care Medicine, Center for Bioethics and Medical Humanities, University of Mississippi Medical Center, Jackson, Mississippi; ${ }^{3}$ Johns Hopkins Berman Institute of Bioethics, Baltimore, Maryland. Correspondence: Renee D. Boss (rboss1@jhmi.edu)

Received 16 April 2015; accepted 5 August 2015; advance online publication 4 November 2015. doi:10.1038/pr.2015.196
} 


\section{Review | seltzer etal.}

children" and "medically fragile children" (11). More recently, the term "children with medical complexity" has been endorsed $(12,13)$ and emphasizes the first-person experiences of these conditions. A definitional framework for children with medical complexity includes four domains: (i) health care service needs, (ii) one or more chronic clinical conditions, (iii) functional limitation(s), and (iv) high health resource utilization (12). Because the population of children with medical complexity is diverse in age, diagnoses, and prognosis, the framework emphasizes care requirements. Examples of children with medical complexity include: the infant with congenital heart disease needing home oxygen, weekly appointments, and multiple cardiac surgeries; the child whose genetic syndrome includes progressive neurological and functional decline and who is fed via gastrostomy tube and will need advanced respiratory support; the adolescent with a traumatic spinal cord injury and quadriplegia, currently wheelchair-bound and dependent on a tracheostomy and ventilator.

The number of children with medical complexity is rising, attributable to medical advances for once-fatal diagnoses. Neonatal and pediatric critical care, nutrition support, and chronic medical therapies have allowed survival of infants and children with complex disease states well beyond their expected life span $(10,14,15)$. These medical interventions mean that many children with congenital conditions including cardiac defects, brain abnormalities, or extreme prematurity will go on to have chronic respiratory and neurodevelopmental morbidities (16-18). Other children with medical complexity accrue increasing morbidities over time, as in cystic fibrosis, cerebral palsy, or genetic syndromes, where recurrent insults or losses in function require escalating levels of support. Mortality for children with varied chronic medical conditions continues to improve, pushing life expectancy-and the need for ongoing health interventions-into early adult years (19).

Families of children with medical complexity must adapt to the evolving care needs that these children sustain. Kuo et al. (20) found a significant family-reported care burden for children with medical complexity compared to children with fewer medical needs, including a median of $2 \mathrm{~h}$ /week in care coordination and 11-20 h/week providing direct home care. These families also reported an average 11-15 physician visits/ year. Such families consistently find the medical system fragmented and difficult to navigate $(20,21)$. They juggle multiple subspecialty visits and home health needs such as oxygen, ventilators, and feeding pumps. The care of children with medical complexity has been described as "outpatient intensive care", alluding to the expansive resources and attention to detail necessary on the part of families and physicians (14).

This complexity can overwhelm even families with resources; data suggest that families of children with medical complexity often maintain unmet health needs irrespective of their income, language, or enrollment in Medicaid (22). Certainly financial constraints compound burdens of care. Over half of families of children with medical complexity report financial problems, out-of-pocket healthcare costs $>\$ 1,000 /$ year, and needing to quit work to meet child health demands (20).
Low-income families experience excess health-related financial burdens (23). Financial burdens are associated with inadequate medical technology use and maintenance, inappropriate supervision of children, nonadherence to treatment, and lack of follow-up (24). These factors in turn are associated with increased hospitalization among children with medical complexity. While children with medical complexity represent only $1 \%$ of the population, they account for up to one-third of child health care expenditures, with the majority of costs associated with inpatient care (24).

Beyond economic risk, multiple other social risk factors can result in, and intensify, a child's medical complexity. Neonatal conditions such as low birth weight, birth defects, and prematurity are associated with poverty, intimate partner violence, maternal depression, and maternal substance use (25-27). Those same social vulnerabilities may undermine a parent's ability to manage their child's medical complexity. When families cannot meet these expectations, the medical foster care system is the primary resource that enables children with medical complexity to reside outside of a hospital or institution.

\section{MEDICAL FOSTER CARE SYSTEM}

The federal foster care program, authorized by title IV-E of the Social Security Act, is administered by states in accordance with federal guidelines. Federal funding is contingent upon state's collection and reporting of defined data related to foster care, and adoptions with state agency involvement, to the Adoption and Foster Care Analysis and Reporting System (AFCARS) (28). The Children's Bureau, within the US Department of Health and Human Services, analyzes data from AFCARS, The National Child Abuse and Neglect Data System, and The National Youth in Transition Database, in order to annually publish the Child Welfare Outcomes Report to Congress (29). Since the 1990s, AFCARS has generated reliable data detailing state and national foster services and outcomes (30). Though significant state variability exists, consistent trends reveal that children most commonly enter foster care in infancy, minority children are over-represented in long-term foster care, and foster child health is poorer than that of the general pediatric population $(2,31)$. Stable long-term placement has been shown to lead to improvements in health status, growth, and educational achievement for foster children (31).

Medical foster care, funded via Medicaid, permits children whose medical complexity outstrips their parents' resources to be cared for outside of institutions. Data regarding medical foster care are not systematically collected. AFCARS does require reporting of "special needs status," but criteria for special needs is determined independently by each state welfare agency and can include minority race, older age, belonging to a sibling group, having another (unspecified) special need, or having a medical condition or disability. For reporting purposes, the state can assign only one special needs criteria for each child, which results in variability of reported medical needs across states (28). AFCARS data for all children adopted with state agency involvement between 1996-2003 demonstrated that $82 \%$ met special needs criteria. During that time period, the 
percentage of children classified as special needs based on a medical condition or disability rose from 13.7 to $24.3 \%$ (28).

Health data about foster children inconsistently distinguish between those entering because of medical complexity, those entering for other reasons but with concurrent medical needs, or those who develop medical complexity after entering foster care. Furthermore, states variably classify foster children with medical needs, use different methods to assess a child's level of medical need, and give inconsistent labels to medical foster homes (32). These inconsistencies undermine quantification of individuals entering foster care specifically because their parents cannot manage their medical needs. Given related data from multiple states regarding medical needs of foster children, we estimate that $5-10 \%$ of the total foster care population, or 20,000-40,000 children annually, are in foster care specifically due to medical complexity (33-35).

\section{HEALTH OUTCOMES FOR CHILDREN IN MEDICAL FOSTER CARE}

The goal of medical foster care is to provide necessary medical care and supervision for children with complex medical conditions. Placing a child with medical complexity in medical foster care with dedicated and trained caretakers should, in theory, lead to lower health care utilization and better health. Yet foster population health is worse than that of the general pediatric population, and worse than one would expect due to financial strain alone $(5,31,36,37)$. Takayama et al. (38) demonstrated that more than twice as many children in foster care used medical equipment, specialist services, or were hospitalized compared to children also receiving Medicaid but not in foster care. Hospitalization rates and lengths of stay are higher than for children with similar health conditions not in foster care $(38,39)$. Newborn hospitalizations are prolonged for foster infants, with as many as $40 \%$ born prematurely or with low birth weight and as many as $80 \%$ exposed to substances prenatally $(39,40)$. Not surprisingly, children with medical complexity utilize a disproportionate amount of medical dollars in the foster care system $(38,39)$. They often require expensive medications, medical equipment, intensive therapies, and close medical supervision.

Among foster children awaiting adoption, AFCARS data from 1998 to 2006 demonstrate a significant increase in the percentage with a diagnosed disability, increasing from 25 to $41 \%$ for boys and 20 to $34 \%$ for girls (41). Medical advances permitting survival of children with intense medical needs, and reductions in disability benefits with welfare reform in the 1990's, likely combined to increase the chance that medically complex children need out-of-home placements (42). The increase also reflects the fact that foster children with complex medical conditions are less likely to exit foster care and be adopted or reunited with their biologic families $(40,41,43)$. The Child Welfare Outcomes Report to Congress for 2009-2012 data showed that states are less successful at finding a permanent home for disabled foster children (median $77.7 \%$, range $23.8-94 \%$ across states) as compared to the general foster population (median 87.3\%, range 67.5-94.2\% across states) (29).
Adoption incentives are less effective for children with disabilities. Increasing adoption payments by $\$ 100$ per month is associated with a $4.5 \%$ increase in the adoption rate of nondisabled boys, but only a $1.9 \%$ increase in the adoption rate of disabled boys (41). The average time from termination of parental rights to adoption for children with a medical condition or disability was 17.1 vs. 14.8 mo for children with no state-defined special need (28). These data underscore that foster children with medical complexity are at high risk of remaining in foster care for prolonged periods of time.

Social and medical risk factors can also contribute significantly to health outcomes. Stein et al. (4) reviewed 2002 National Health Interview Survey data from 8,174 children and concluded that children who experienced both the highest biomedical and social risk factors together had significantly greater odds of poorer health and higher health care utilization than those with only biomedical risks. Children entering foster care have typically already experienced multiple psychosocial stressors such as parental substance abuse, mental illness, poverty, or homelessness (44). Social risks have a cumulative effect, and can result in toxic stress, or the "extreme, frequent, or extended activation of the stress response, without the buffering of a supportive adult" (45). Toxic stress can cause biologic adaptations of the brain, neuroendocrine response, and immune system, leading to poor health outcomes that persist into adulthood (45). Because children with medical complexity often spend long periods in medical foster care, it is important to understand how the foster care environment might impact their health outcomes.

\section{MEDICAL FOSTER HOME ENVIRONMENT}

A minority of all foster homes serves as medical foster homes, though states use financial incentives that aim to increase the size of this pool. Daily foster parent reimbursement rates for medically complex children are generally two to three times the basic rate (32). Each state determines how many medically complex and total foster children can be placed in one home. Because daycare is often expressly prohibited for foster children with medical complexity, compelling in-home care at all times, this limits foster parent work outside the home and incentivizes accepting several medically complex foster children at one time. This raises concerns about the quality of care those children can receive in light of their multiple, competing daily needs.

Training of medical foster parents, medical foster care case workers, and supervisors to manage the needs of medically complex children varies by state as well (40). Data describing medical foster families are not robust, but suggest that foster parents often feel inadequately prepared to care for children with medical complexity. Greiner et al. (46) reported that foster parents frequently receive fragmented medical information about children placed in their care, such as missing information about medication schedules and prescriptions. They report feeling ill-prepared to navigate the health system and access services, and worry that medical information is withheld when a child is placed in their care to deter their potential 


\section{\begin{tabular}{l|l} 
Review & Seltzer et al.
\end{tabular}}

refusal. In fact, approximately one third of licensed foster caregivers lack placements because they are reluctant to take on children with medical complexity (47). Because these children have often had multiple foster home placements, continuity of communication about the child's health problems can be disrupted (5). Foster parents complain about agency policies that delay their notification of a potential placement until just before the child is discharged from the hospital, such that they are rushed to learn medical care skills. And foster parents also describe how failures of respite and home nursing care create excessive burdens (47). Those caring for children with life-limiting conditions report receiving little help or support preparing for the child's death (47).

Caring for a foster child with medical complexity impacts the lifestyle and day-to-day experiences of the entire foster family (47). Families report stress and financial strains associated with the child's care. Though the foster care system may provide medical foster parents with generalized training in delivering medications or special feedings, foster parents are rarely prepared for the lived experience of being intensive medical caregivers and advocates. They also describe difficulty accessing and coordinating with other professionals involved in the child's life (48). As foster parents accrue time with a child in their care, many become authorities on the child's daily needs and medical concerns. This knowledge, or lack thereof, is a crucial component of the ongoing decisions prompted by the child's evolving health status.

\section{SHARED MEDICAL DECISION-MAKING FOR FOSTER CHILDREN}

Children with medical complexity in foster care deserve special consideration with respect to medical decision-making. Many endure life-limiting conditions that trigger recurrent considerations about the benefits vs. burdens of medical and surgical interventions. Their unique medical and social risks may impact prognostic certainty. It is important for clinicians to know who should be included in important medical decisions for these children and to consider how foster care itself should be factored into medical decisions, if at all.

States assign variable authority to foster parents to obtain medical care for a child. Foster parents are typically responsible for determining when a child needs medical attention, and may possess information important to medical decisions $(46,49)$. But unless parental rights are terminated or relinquished, biologic parents are legal custodians and usually retain authority for consenting to medical treatment (49). In some locales, biologic parents may sign generic consents for routine heath care, but nonroutine evaluations and interventions require specific consent from the biologic parent (31). Attempts to locate a biologic parent for consent can delay medical care, or may compel a court-appointed guardian or court-ordered treatment (49).

In practice, serious medical decisions for foster children with medical complexity are variably shared between biological parents, foster parents, caseworkers, and clinicians. Perspectives may conflict, as when a biologic parent refuses treatment that a foster parent believes is in the child's best interest. Policies of limiting consent only to biologic parents enables parents with minimal involvement in their child's life to request burdensome therapies without subsequent responsibility for witnessing the impact on the child or providing the associated care. Considerations about limiting life-sustaining therapies are particularly complex, especially when biologic families are difficult to engage. State legal systems will often provide consent to escalating interventions that may prolong a child's life, but are reluctant to withhold or withdraw therapies without parental consent (50).

Little has been written about whether ethical frameworks for decision-making regarding medical interventions for children in medical foster care should differ in any way from decisionmaking for similar children with more stable circumstances. Health outcomes for complex children are conditional on daily care received outside of hospitals and physician offices; unstable social environments can undermine treatment success and increase burdens for a child. When the medical benefits of a proposed intervention are sufficiently uncertain, and the burden to the child not negligible, it could be argued that the social risks of medical foster care further undermine medical benefit and should tip the balance against that intervention. Others might argue that children who have already faced more than their share of adverse social experiences deserve a greater allocation of medical resources than do children without such adversities (51), and clinicians have a duty to care for these children in the hospital indefinitely if no adequate outpatient care is available. Still others would argue that physicians have a responsibility to advocate for the social and systematic reforms that could enable more biologic and foster parents to provide quality care for these children (52).

\section{NEXT STEPS}

Overall, there are few quality studies to help us understand whether children with medical complexity in the foster care system achieve similar health outcomes as their peers who are not in foster care. The existing literature, laws, and policy statements do provide some overlapping clinical and policy recommendations for how to optimize health outcomes overall for both children in foster care as well as for children with medical complexity. Evidence suggests that outcomes for both populations could be improved with comprehensive and coordinated health care via medical homes and shared health information $(5,53,54)$.

The Fostering Connections to Success and Increasing Adoption Act, signed into law in 2008, mandates the use of medical homes for foster children so they can maintain the same physician even if their placement changes (5). Healthy People 2010 also advocates that children with special health care needs should have medical homes to provide coordinated, ongoing, comprehensive care (54). We continue to lack reliable information about whether medically complex children in foster care are cared for in medical homes or whether those settings are consistently achieving improved health outcomes (5). The medical home should be the single entry point to access care or referrals and distribute health information 
among various providers, family, and agencies. Care coordination involves identifying, prioritizing, and monitoring a child's needs and implementing a care plan based on collective input from involved guardians and services (54). Coordinated care in a medical home is associated with improved health outcomes, reduced hospital admissions and length of stay, reduced emergency visits, more effective use of services, and improved patient and family satisfaction $(53,54)$.

There is also benefit to using a tangible document to share important health information. A "care plan" or "medical passport" is a written document that outlines a child's unique social and medical issues $(5,55)$. It is carried by the parent and shared with clinicians as an easily accessible and comprehensive summary of the child's health (55). Parents are less stressed when they can rely on a written care plan vs. having to recount information on their own (55); this may particularly assist foster parents who are less familiar with the health history.

Pediatricians at the center of medical homes for these children have complex responsibilities including eliminating gaps in relevant medical and social information, providing comprehensive care, and serving as a liaison to specialists in and out of the hospital (44). During the inpatient hospitalizations that occur frequently for these children, primary clinicians play important roles in critical decision-making (56). This commitment of time and resources to provide quality care may deter pediatricians from serving these patients (31). To counter this, third party payers must be lobbied to reimburse for time spent in care coordination, documentation, care plan development and oversight, and counseling (54). Some child welfare agencies utilize Title V Medicaid funding dedicated to case management services in order to help with care coordination (54), but this does not currently address physician reimbursement.

Pediatricians who are motivated to take on complex patients also require targeted training and resources to provide the appropriate level of care (57). In 2003, the Institute of Medicine recommended that all pediatric clinicians should be trained to provide medically complex patients with safe, efficient, effective, and equitable care (57). This recommendation has yet to promote widely available continuing medical education on topics relevant to complex care management, including care coordination, shared decision making, setting and communicating treatment goals, and working with interprofessional teams $(14,57)$. All pediatric clinicians should receive training about navigating their state's foster care system and collaborating with foster families (49).

Research agendas should examine how children with medical complexity in medical foster care differ from those cared for by biologic parents, particularly with regard to health outcomes, healthcare utilization, decision-making, goals of care, and quality of life. Additional areas that deserve further exploration include how best to (i) track medical foster care placements and outcomes, (ii) modify the medical consent process for children in medical foster care to encourage timely treatment, (iii) maintain medical foster care databases to prevent fragmented health information, (iv) improve foster parent training and resources focused on children with medical complexity, and (v) provide biologic parents with social services and supports to promote reunification with their child. As more data are collected about the growing population of children with medical complexity in medical foster care, providers and policymakers will be better equipped to participate in child welfare reform and advocate for policy and legislative changes to optimize care.

\section{CONCLUSION}

Children with medical complexity are a unique population with intensive medical and social needs. When their needs surpass the abilities of biologic parents, these children often enter medical foster care, a decision driven by a desire to enable the child to leave the hospital setting. Medical foster care has the potential to provide many advantages for these children, but systematic reforms are needed to make this care more efficient, cost-effective, and comprehensive.

\section{ACKNOWLEDGMENT}

The authors would like to thank Blair Anton, MLIS, of the William H. Welch Medical Library, for her help in locating resources for this Review.

\section{STATEMENT OF FINANCIAL SUPPORT}

R.D.B.'s effort was supported by the Cambia Health Foundation, Portland, OR.

Disclosures: There are no financial disclosures or conflicts of interest.

\section{REFERENCES}

1. Children's Bureau. Administration on Children, Youth and Families. U.S. Department of Health and Human Services. Trends in Foster Care and Adoption: FFY 2002-FFY 2013. http://www.acf.hhs.gov. 2014.

2. Wildeman C, Emanuel N. Cumulative risks of foster care placement by age 18 for U.S. children, 2000-2011. PLoS One 2014;9:e92785.

3. Larson K, Russ SA, Crall JJ, Halfon N. Influence of multiple social risks on children's health. Pediatrics 2008;121:337-44.

4. Stein RE, Siegel MJ, Bauman LJ. Double jeopardy: what social risk adds to biomedical risk in understanding child health and health care utilization. Acad Pediatr 2010;10:165-71.

5. Mekonnen R, Noonan K, Rubin D. Achieving better health care outcomes for children in foster care. Pediatr Clin North Am 2009;56:405-15.

6. Wildeman C, Waldfogel J. Somebody's Children or Nobody's Children? How the Sociological Perspective Could Enliven Research on Foster Care. Annu Rev Sociol 2014;40:599-618.

7. Newacheck PW, Strickland B, Shonkoff JP, et al. An epidemiologic profile of children with special health care needs. Pediatrics 1998;102(1 Pt 1): 117-23.

8. McPherson M, Arango P, Fox H, et al. A new definition of children with special health care needs. Pediatrics 1998;102(1 Pt 1):137-40.

9. Institute of Medicine (U.S.). Committee on Identifying Priority Areas for Quality Improvement. Adams K, Corrigan J. Priority Areas for National Action: Transforming Health Care Quality. National Academies Press: Washington, DC, 2003.

10. Burns KH, Casey PH, Lyle RE, Bird TM, Fussell JJ, Robbins JM. Increasing prevalence of medically complex children in US hospitals. Pediatrics 2010;126:638-46.

11. Srivastava R, Stone BL, Murphy NA. Hospitalist care of the medically complex child. Pediatr Clin North Am 2005;52:1165-87, x.

12. Cohen E, Kuo DZ, Agrawal R, et al. Children with medical complexity: an emerging population for clinical and research initiatives. Pediatrics 2011;127:529-38.

13. Simon TD, Berry J, Feudtner C, et al. Children with complex chronic conditions in inpatient hospital settings in the United States. Pediatrics 2010;126:647-55.

14. Hall DE. The care of children with medically complex chronic disease. J Pediatr 2011;159:178-80. 


\section{Review Seltzer etal.}

15. Strauss D, Shavelle R, Reynolds R, Rosenbloom L, Day S. Survival in cerebral palsy in the last 20 years: signs of improvement? Dev Med Child Neurol 2007;49:86-92.

16. Horbar JD, Badger GJ, Carpenter JH, et al.; Members of the Vermont Oxford Network. Trends in mortality and morbidity for very low birth weight infants, 1991-1999. Pediatrics 2002;110(1 Pt 1):143-51.

17. Wilson-Costello D, Friedman H, Minich N, Fanaroff AA, Hack M. Improved survival rates with increased neurodevelopmental disability for extremely low birth weight infants in the 1990s. Pediatrics 2005;115 :997-1003.

18. Kaiser JR, Tilford JM, Simpson PM, Salhab WA, Rosenfeld CR. Hospital survival of very-low-birth-weight neonates from 1977 to 2000. J Perinatol 2004;24:343-50.

19. Feudtner C, Hays RM, Haynes G, Geyer JR, Neff JM, Koepsell TD. Deaths attributed to pediatric complex chronic conditions: national trends and implications for supportive care services. Pediatrics 2001;107:E99.

20. Kuo DZ, Cohen E, Agrawal R, Berry JG, Casey PH. A national profile of caregiver challenges among more medically complex children with special health care needs. Arch Pediatr Adolesc Med 2011;165:1020-6.

21. Ghose R. Complications of a medically complicated child. Ann Intern Med 2003;139:301-2.

22. Kuo DZ, Goudie A, Cohen E, et al. Inequities in health care needs for children with medical complexity. Health Aff (Millwood) 2014;33:2190-8.

23. Newacheck PW, Inkelas M, Kim SE. Health services use and health care expenditures for children with disabilities. Pediatrics 2004;114:79-85.

24. Coller RJ, Nelson BB, Sklansky DJ, et al. Preventing hospitalizations in children with medical complexity: a systematic review. Pediatrics 2014;134:e1628-47.

25. Alhusen JL, Lucea MB, Bullock L, Sharps P. Intimate partner violence, substance use, and adverse neonatal outcomes among urban women. J Pediatr 2013;163:471-6.

26. Staneva A, Bogossian F, Pritchard M, Wittkowski A. The effects of maternal depression, anxiety, and perceived stress during pregnancy on preterm birth: A systematic review. Women Birth 2015;28:179-93.

27. Pawluk MS, Campaña H, Gili JA, et al. Adverse social determinants and risk for congenital anomalies. Arch Argent Pediatr 2014;112:215-23.

28. North American Council on Adoptable Children. AFCARS adoption data research brief number 4: special needs and disabilities. http://www.nacac. org/adoptionsubsidy/AFCARSspecialneeds.pdf. 2006.

29. Children's Bureau. Administration on Children, Youth and Families. U.S. Department of Health and Human Services. Child welfare outcomes 20092012 report to congress. http://www.acf.hhs.gov/programs/cb/resource/ cwo-09-12. 2013.

30. Tiberg I, Katarina SC, Carlsson A, Hallström I. Children diagnosed with type 1 diabetes: a randomized controlled trial comparing hospital versus home-based care. Acta Paediatr 2012;101:1069-73.

31. Simms MD, Dubowitz H, Szilagyi MA. Health care needs of children in the foster care system. Pediatrics 2000;106(4 Suppl):909-18.

32. Brogan TV, Hall M, Williams DJ, et al. Variability in processes of care and outcomes among children hospitalized with community-acquired pneumonia. Pediatr Infect Dis J 2012;31:1036-41.

33. Children's Bureau. Administration on Children, Youth and Families. U.S. Department of Health and Human Services. The AFCARS Report. http:// www.acf.hhs.gov/sites/default/files/cb/afcarsreport20.pdf. 2013.

34. Children's Bureau. Administration on Children, Youth and Families. U.S. Department of Health and Human Services. A report to congress on barriers \& success factors in adoptions from foster care: perspectives of families and staff. http://www.acf.hhs.gov/sites/default/files/cb/report_congress_ barriers.pdf. 2007.

35. Hochstadt NJ, Jaudes PK, Zimo DA, Schachter J. The medical and psychosocial needs of children entering foster care. Child Abuse Negl 1987;11: 53-62.

36. Steele JS, Buchi KF. Medical and mental health of children entering the utah foster care system. Pediatrics 2008;122:e703-9.
37. Ahrens KR, Garrison MM, Courtney ME. Health outcomes in young adults from foster care and economically diverse backgrounds. Pediatrics 2014;134:1067-74.

38. Takayama JI, Bergman AB, Connell FA. Children in foster care in the state of Washington. Health care utilization and expenditures. JAMA 1994;271:1850-5.

39. Halfon N, Berkowitz G, Klee L. Children in foster care in California: an examination of Medicaid reimbursed health services utilization. Pediatrics 1992;89(6 Pt 2):1230-7.

40. United Cerebral Palsy and Children's Rights. Forgotten Children: A case for action for children and youth with disabilities in foster care. http:// www.childrensrights.org/wp-content/uploads/2008/06/forgotten_children_children_with_disabilities_in_foster_care_2006.pdf. 2006.

41. Argys L, Duncan B. Economic incentives and foster child adoption. Demography 2013;50:933-54.

42. Simms MD, Freundlich M, Battistelli ES, Kaufman ND. Delivering health and mental health care services to children in family foster care after welfare and health care reform. Child Welfare 1999;78:166-83.

43. Winokur M, Holtan A, Batchelder KE. Kinship care for the safety, permanency, and well-being of children removed from the home for maltreatment. Cochrane Database Syst Rev 2014;1:CD006546.

44. Committee on Early Childhood and Adoption and Dependent Care, American Academy of Pediatrics. Health care of young children in foster care. Pediatrics 2002;109:536-41.

45. Johnson SB, Riley AW, Granger DA, Riis J. The science of early life toxic stress for pediatric practice and advocacy. Pediatrics 2013;131:319-27.

46. Greiner MV, Ross J, Brown CM, Beal SJ, Sherman SN. Foster Caregivers' Perspectives on the Medical Challenges of Children Placed in Their Care: Implications for Pediatricians Caring for Children in Foster Care. Clin Pediatr (Phila) 2015;54:853-61.

47. Lauver LS. Parenting foster children with chronic illness and complex medical needs. J Fam Nurs 2008;14:74-96.

48. Brown JD, Rodger S. Children with disabilities: Problems faced by foster parents. Child Youth Serv Rev 2009;31:40-6.

49. Lauver LS. The lived experience of foster parents of children with special needs living in rural areas. J Pediatr Nurs 2010;25:289-98.

50. Boss RD. End-of-life decision-making for infants abandoned in the neonatal intensive care unit. J Palliat Med 2008;11:109-11.

51. Bærøe K, Bringedal B. Just health: On the conditions for acceptable and unacceptable priority settings with respect to patients' socioeconomic status. J Med Ethics 2011;37:526-9.

52. Kelley M, Unguru Y, Myers GD, Lantos JD. An 8-year-old foster child with behavioral problems who needs a bone marrow transplant. Pediatrics 2012;130:936-40.

53. Looman WS, Antolick M, Cady RG, Lunos SA, Garwick AE, Finkelstein SM. Effects of a Telehealth Care Coordination Intervention on Perceptions of Health Care by Caregivers of Children With Medical Complexity: A Randomized Controlled Trial. J Pediatr Health Care 2015;29:352-63.

54. American Academy of Pediatrics Council on Children with Disabilities. Care coordination in the medical home: integrating health and related systems of care for children with special health care needs. Pediatrics 2005;116:1238-44.

55. Adams S, Cohen E, Mahant S, Friedman JN, Macculloch R, Nicholas DB. Exploring the usefulness of comprehensive care plans for children with medical complexity (CMC): a qualitative study. BMC Pediatr 2013;13:10.

56. Hagvall M, Ehnfors M, Anderzen-Carlsson A. Experiences of parenting a child with medical complexity in need of acute hospital care. J Child Health Care, e-pub ahead of print 28 October, 2014.

57. Bogetz JF, Bogetz AL, Gabhart JM, Bergman DA, Blankenburg RL, Rassbach CE. Continuing education needs of pediatricians across diverse specialties caring for children with medical complexity. Clin Pediatr (Phila) 2015;54:222-7. 